\title{
Medical Miscellanea In Lighter Vein
}

\author{
Capt R N Villar
}

$M B, B S, R A M C$

I don't suppose that I shall see a patient quite the same ever again or at least it will be a while until I do. I had been sorting through the myriads of coughs, colds and skin rashes of my week-end on in a military hospital when a small and frightened woman careered round the corner with a young child in tow. She began to address my white coat and stethoscope. "Are you a doctor?" she said in an Irish accent. I had to confess that I was despite my bedraggled and unshaven appearance from a sequence of disturbed nights the week before. Uniform has never looked particularly good on me at the best of times and today I was looking singularly scruffy. Some people manage to look smart whatever the conditions but I have to admit to being an exception.

Only partly convinced, the woman thrust her child towards me proclaiming in a loud voice for all to hear that the youngster had managed to get a cabbage leaf stuck up its nose and had been sneezing incessantly for the past 24 hours. My task, she added, in a voice that would have subdued the most ardent of Major-Generals, was to remove it and she would be back in an hour to make sure that I had. With that she left, leaving me the impossible job of aiming the tips of a pair of nasal dressing forceps at the moving target of a nostril in an irate and bawling child. I never did succeed and would still be there now if the patient had not sneezed the leaf out and cured herself. I sat back exhausted and began to think of suitable stories to tell the mother about my professional prowess as a leaf-extractor but instead started to day-dream about the things $I$ had been up to this week-end.

I had spent most of Friday night on the Burns Unit looking after two patients with caustic soda burns to the eyes and abdomen that had been referred by the local civilian hospital. I never did feel confident with eyes, probably because as a student it was never encouraged, so I was very glad to see the face of our consultant ophthalmologist appear round the corner. He had seen it all a thousand times before and set about examining these two poor fellows with a professionalism that could not fail to impress the most sceptical of individuals. I remember all my doubts prior to joining the Army when I was terrified that my standards would drop and that total professional suicide was inevitable. Now that I am a fully-fledged military doctor I cannot conceive why I was so worried when the past 3 years of service have without doubt been the most interesting and action-packed of my life and my bosses among the most capable in the United Kingdom. They manage to keep me in control anyway, which my family have always said is impossible.

The eyes man drifted off leaving me with a comprehensive list of instructions of all the things that I should do. As always, no sooner had I settled down to arranging them when my bleep went off for at least the fifty-fourth time that day. Back to Casualty I had to go, on this occasion to sort oute a traumatic rupture of the ear-drum in a young girto who had got into a brawl with her boy-friend. Sheo wasn't too certain whether it was her ear or hero feelings that hurt the most but a little Hippocratios encouragement sent her on her way with a smilingo face. In this hospital we don't have the benefit of a $\vec{\varnothing}$ full-time Casualty Officer and so as resident surgeono of the day you can spend most of your time run ning up and down between the wards and Casualty rather like a demented yo-yo. It is a technical impos? sibility keeping both happy at the same time, though, when I come to think of it, life was exactly the same in the NHS.

By now it was late Saturday morning and my sleepless night was beginning to tell. The ear-drum had just walked happily out of the hospital doors and for the first time since I had come on Casualty appeared empty. Time for bed I reckoned. I had got as far as taking off my tie when the dreaded box went off again. This time it was my ward demanding why I had omitted to do the routine round this morning and did I know that there were five cytotoxics to give before lunch? My sense of humour began to plummet irreversibly, my tie went back on, and off to the ward I went. I work for the main surgical oncology unit in the Army, a 36bedded affair that is permanently full. A lot of patients are my age or younger making it sometimes quite difficult not to get emotionally involved. Teratomas are commonplace and melanomas twoa-penny, whilst breast tumours in wives we see every day. Add to these a liberal sprinkling of such oncological exotica as Schwannomas and carcinoids 
and you have got yourself a pretty impressive and often confusing collection of neoplasms. Each time a new admission arrives he will be put through the standard cycle of diagnosis, staging, and ultimate treatment, the latter being frequently unpleasant. It makes my heart bleed sometimes to have to give such toxic drugs to young fellows who you know will one day succumb to the inexorable advance of their disease. The only patients I can safely smile at are the teratomas who seem to have a pretty good chance of cure. If I was obliged to have a cancer I think I would opt for a teratoma - thank heavens I'm a man and don't have large breasts.

By mid-Saturday afternoon the ward work and cytotoxics were over though a case of small intestinal obstruction was beginning to brew under the physicians and an appendicectomy was on its way from a GP. As if these were not enough, one of the more established operating theatre technicians had presented at the main reception desk with bellyache and was turning a paler shade of grey on the floor between a couple of ashtrays. He had a pretty extensive tropical history and would have done quite well for an amoebic abscess, so I put: him to bed and starved him in case things got out of hand. Thus the week-end progressed with a slow trickle of cases coming through all the time. Sometimes I would be in theatre and sometimes outside but by nine o'clock on Saturday night I had made it to bed for my first undisturbed sleep in a long while. They don't happen very often and are worth remembering when they do.
Sunday was another memorable occasion as discovered to my cost over breakfast. It was Remembrance Day and a doctor was needed at the $\frac{\pi}{8}$ Cenotaph Parade to look after all the spectators should they fall ill during the ceremony. I justo happened to be eating my toast and marmalade atc the time the telephone rang so within the space of a: couple of hours I was to be transformed from acs haggard hospital doctor to a smart, upright individuato in shining blue uniform and gleaming buttons. Youo already know what I think of uniforms but I haven to confess to being secretly proud of my appearance as one dignitary after another passed before men and acknowledged my rather rusty salutes. I had. hardly any work to do so was able to relax and? enjoy the proceedings though one elderly man did come up to me with an umbilical hernia that $I$ reduced for him in the back of a nearby lorry. Heg was almost unbearably grateful for my efforts though steadfastly rejected my offer to repair the? defect the following day. You cannot give people a quicker service than that so I returned to the hospital mortally offended that he didn't trust my surgical skills and changed back into my whice coat in a sulk.

So here am I back in Casualty with a queteof twenty patients outside. Monday is coming a ofdo there's the boss' round to prepare so there is for time for day-dreams right now. If you've gotoa moment and want to drop by, come and let me she $E_{N}$ you what it's like. It's fun, it's busy and oftenoo hard work and it's something I shall always enje 